\title{
Optimal design of SSSC and crowbar parameters for performance enhancement of Egyptian Zafrana wind farm
}

\author{
Ahmed Rashad $^{1,2} \cdot$ Salah Kamel $^{1} \cdot$ Francisco Jurado $^{2}\left(\right.$ Mahmoud Rihan $^{3} \cdot$ Mohamed Ebeed $^{4}$
}

Received: 21 April 2020 / Accepted: 6 September 2021 / Published online: 6 October 2021

(c) The Author(s) 2021

\begin{abstract}
Zafarana Wind Park is considered the largest wind farm in Middle East. By the year 2022, Zafarana wind farm will inject $545 \mathrm{MW}$ to Egypt national electric network (ENEN). This wind farm has been connecting to ENEN in stages (eight stages) from ten years ago. Each stage represents a project of wind farm. Hence, the impact of the emergency condition of ENEN on the performance of the installed stage of Zafarana Wind Park should be studied. Moreover, determining the possible method to reduce the side effects of the emergency condition of ENEN on the installed stage of Zafarana Wind Park becomes an important issue. In this paper, a combination between Static Synchronous Series Compensator (SSSC) and crowbar (CroSSSC) is used to enhance the performance of the one installed stage of Zafarana Wind Park. The studied stage of Zafarana Wind Park is Zafarana Z1 wind farm (Z1). Zafarana Z1 wind farm represents that first stage of Zafarana Wind Park that was connected to ENEN. Hence, the paper takes Zafarana Z1 wind farm as the studied case to examine the impact of Cro-SSSC. The crowbar is used to protect the power components of the SSSC from the high current during grid fault condition. Also, in this paper multi-objective lightning attachment procedure optimization algorithm (LAPO) and the sine cosine algorithm (SCA) are used to evaluate and tune the control gains of SSSC and the value of crowbar's resistance. This step is important in order to determine the values of the control's gains of SSSC and the value of crowbar resistance which suit the studied system (one installed stage of Zafarana Wind Park). The sliding mode control (SMC) is used as an example of nonlinear control of SSSC. Also, a hybrid of LAPO and SMC is used to improve the performance of Zafarana Z1 during faults. The results of LAPO, SCA and SMC are compared during three-phase fault and single line to ground fault applied to the studied system.
\end{abstract}

Keywords Combined wind farm · Optimization algorithm · Sine cosine algorithm · Static synchronous series compensator * Crowbar $\cdot$ Sliding mode control (SMC)

$\triangle$ Francisco Jurado

fjurado@ujaen.es

Ahmed Rashad

ahmedmmrashadar@gmail.com

Salah Kamel

skamel@aswu.edu.eg

Mahmoud Rihan

samehrihan@gmail.com

Mohamed Ebeed

mebeed@eng.sohag.edu.eg

1 Department of Electrical Engineering, Faculty of Engineering, Aswan University, Aswân 81542, Egypt

2 Department of Electrical Engineering, University of Jaén, 23700 EPS Linares, Jaén, Spain

3 Department of Electrical Engineering, South Valley University, Qena, Egypt

4 Department of Electrical Engineering, Faculty of Engineering, Sohag University, Sohâg, Egypt

\section{Introduction}

\subsection{General introduction}

At the beginning of this century, Egypt intended to the expansion of the establishment of industrial cities. This has led to an increase in the demand of electrical energy needed for these industrial cities. The main challenge which faces the Egyptian government is how to increase the electric energy production without increase the fuel cost. The expanding in generating electric energy from renewable energy is the best chose to face this challenge. The geographical location of Egypt has granted Egypt advantages such as solar radiation reaches $24 \mathrm{MJ} / \mathrm{m}^{2}[1,2]$, and wind speed reaches 15 $\mathrm{m} / \mathrm{s}$ at coastal areas [3]. This engorges Egyptian government to develop plans for the establishment of renewable energy plants. It is known that the generating electricity from wind energy is lower cost than the generating electricity from solar energy. Hence, Egyptian government starts their steps by 
installing wind farms, especially in Red Sea coast. Hence, this paper focuses on wind farms which have been installed and interconnected with the Egypt national electric network (ENEN).

\subsection{Literature survey}

There are many articles that studied the issue of enhancing the relation between wind farms and their interconnected grids. These efforts revolve about using flexible AC transmission system (FACTS) to improve the impact of wind farms interconnected grid or using artificial intelligence methods to improve the performance of FACTS integrated with wind farms. In this paper, literature review will focus on the efforts which have been achieved to improve the performance of wind farms based on SCIG (SCIG-WF). A proposed control method based on hierarchal PI-fuzzy-PI controller was discussed in [4] to improve the frequency control of SCIGWF during an unbalance between load demand and power generated. In Ref. [5], Static Synchronous Compensator (STATCOM) was used to regulate the voltage of SCIGWF during fault condition. Enhancing the transient stability of SCIG-WF by improving the control system of STATCOM was introduced in [6]. The artificial neural network (ANN) was proposed to find the optimal value of STATCOM controller in [7]. The optimal place of integrated unified power quality conditioner (i-UPQC) was investigated in [8] to improve the power quality of distribution system interconnected to SCIG-WF. Static Synchronous Series Compensator (SSSC) based on ANN was used to improve different type of wind turbines including SCIG wind farms in [9]. Low Voltage Ride Through (LVRT) capability of SCIG-WF was improved using unified inter-phase power controller (UIPC) in [10]. In Ref. [11], Center-node Unified Power Flow Controller was used to enhance different types of wind farms even SCIG-WF. The crowbar was used to improve the relationship between wind farms and interconnected grid. Most of these articles were based on using crowbar as inner protection to stator of doubly fed induction generators (DFIG) such as in [12-14]. In Ref. [15], crower is used as outer protection to improve the impact of wind farm base on SCIG and DFIG. The performance and load flow study of Zafarana wind farm was presented in [16]. The information and communication technology (ICT)-based ANN was investigated in [17] to improve the control system of Zafarana wind farm. Improving the performance of Zafarana wind farm using STATCOM was investigated in [18]. The impact of Harmonic resonance due to overvoltage on the transformers connected the Zafarana wind farm to ENEN was studied in [19].

LAPO algorithm is an efficient physical-based technique which conceptualizes from behavior of Lightening in natural [20,21]. LAPO algorithm was successfully implemented for solving many optimization problems where in [22] LAPO has been used for Optimal Power Flow problem (OPF) solution with STATCOM. The authors in [22] implemented the LAPO algorithm for the wrapper feature selection optimizations. In [22], LAPO algorithm was utilized to determine the most fitted parameters of the UPFC device. In [23], the OPF problem has been solved by the LAPO.

Sine cosine algorithm (SCA) technique is a new population-based optimization technique proposed by Mirjalili [24]. The SCA is also applied for solving many optimization problems where the authors In [25], solved optimization the bend photonics crystal. Attia et al. [26] implemented the SCA for OPF solution. The authors in [27] solved the optimal reactive power dispatch problem with inclusion of series and shunt controller using the SCA.

SMC features with its ability to control the performance of systems without concerning the effect of uncertainty factors. The effect of the phenomena of chattering represents the major disadvantage of this type of control. There are some articles which deal with this issue to overcome the effect of these phenomena such as [28]. In [29], SMC with adjusting output feedback was used to control the power and speed of wind turbines. A hybrid of fuzzy logic control and secondorder SMC was applied to unified power flow controller in [30]. In [31], a developed method of SMC was proposed to reduce the phenomena of chattering and investigate the optimal power extracted from wind.

\subsection{Contribution of paper}

In this paper, the unsatisfactory performance of Zafarana wind farm especially disconnection from ENEN during fault condition is handled using proposed Cro-SSSC. The CroSSSC is composed of a combination of crowbar and SSSC. The crowbar is combined with SSSC to protect the SSSC from being damaged due to high current during fault where SSSC is connected in series with the transmission line. In this paper, LAPO and SCA algorithms are used to determine the appropriate values of the crowbar resistance and control parameters of SSSC. These values of the crowbar resistance and control parameters of SSSC are determined to fit with studied system of Zafaranal wind farm. Also, SMC is proposed to control the SSSC based on the values of the control parameters of SSSC obtained by optimization. The performance of Zafaranal wind farm with Cro-SSSC when it is tuned by LAPO, SCA and SMC is compared with Zafarana1 wind farm Z1 without Cro-SSSC during three phase and single line to ground faults.

\section{Description of Zafarana Wind Park}

Zafarana Wind Park had been designed to be the biggest wind farm in the Middle East. Zafarana Wind Park represents an 
Table 1 The eight wind farms of Zafarana Wind Park

\begin{tabular}{llll}
\hline Wind farm's name & Power capacity & Number of wind turbines & Type of wind turbines \\
\hline Zafarana1 wind farm (Z1) & $30 \mathrm{MW}$ & 50 & Nordex-N43 \\
Zafarana2 wind farm (Z5) & $33 \mathrm{MW}$ & 55 & Nordex-N43 \\
Zafarana3 wind farm (Z3) & $30 \mathrm{MW}$ & 50 & Nordex-N43 \\
Zafarana4 wind farm (Z4) & $47 \mathrm{MW}$ & 71 & Vestas-V47 \\
Zafarana5 wind farm (Z5) & $85 \mathrm{MW}$ & 100 & Gamesa-G52 \\
Zafarana6 wind farm (Z6) & $80 \mathrm{MW}$ & 94 & Gamesa-G52 \\
Zafarana7 wind farm (Z7) & $120 \mathrm{MW}$ & 141 & DFIG- Under install \\
Zafarana8 wind farm (Z8) & $120 \mathrm{MW}$ & 141 & DFIG- Under install \\
\hline
\end{tabular}

Fig. 1 The site of Zafarana Wind Park

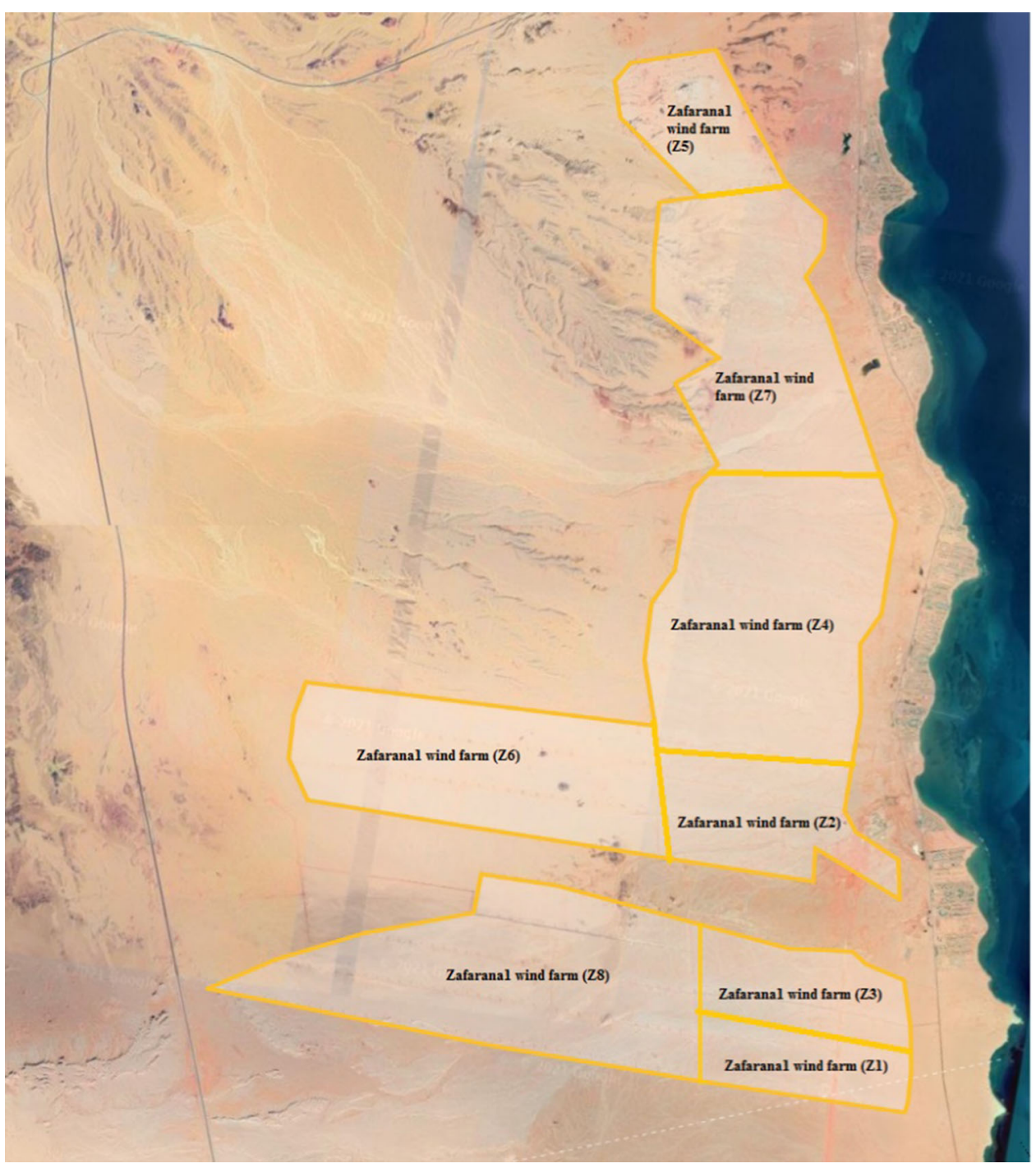

example of cooperation between a set of countries (DanishGarman-Japan-Spain) and the Egyptian government. The allocated area of Zafarana Wind Park is $150 \mathrm{~km}^{2}$ that lies between $\left(32^{\prime} 36^{\prime \prime}\right)$ and $\left(29^{\prime} 06^{\prime \prime}\right)$ latitude angle equal [16-19]. The average wind speed in site of Zafarana Wind Park is 10 $\mathrm{m} / \mathrm{s}$. Zafarana Wind Park composes eight stages; each stage represents a project of a separate wind farm. Six wind farms are already installed and connected to ENEN, while the last two stages will be completed by year 2022 [16-19, 32, 33]. Table 1 and Fig 1 show the eight wind farms of Zafarana Wind Park [16-19, 32, 33]. 
Fig. 2 The SLD of Zafarana Z1 wind farm
Table 2 The parameters of Nordex-N43

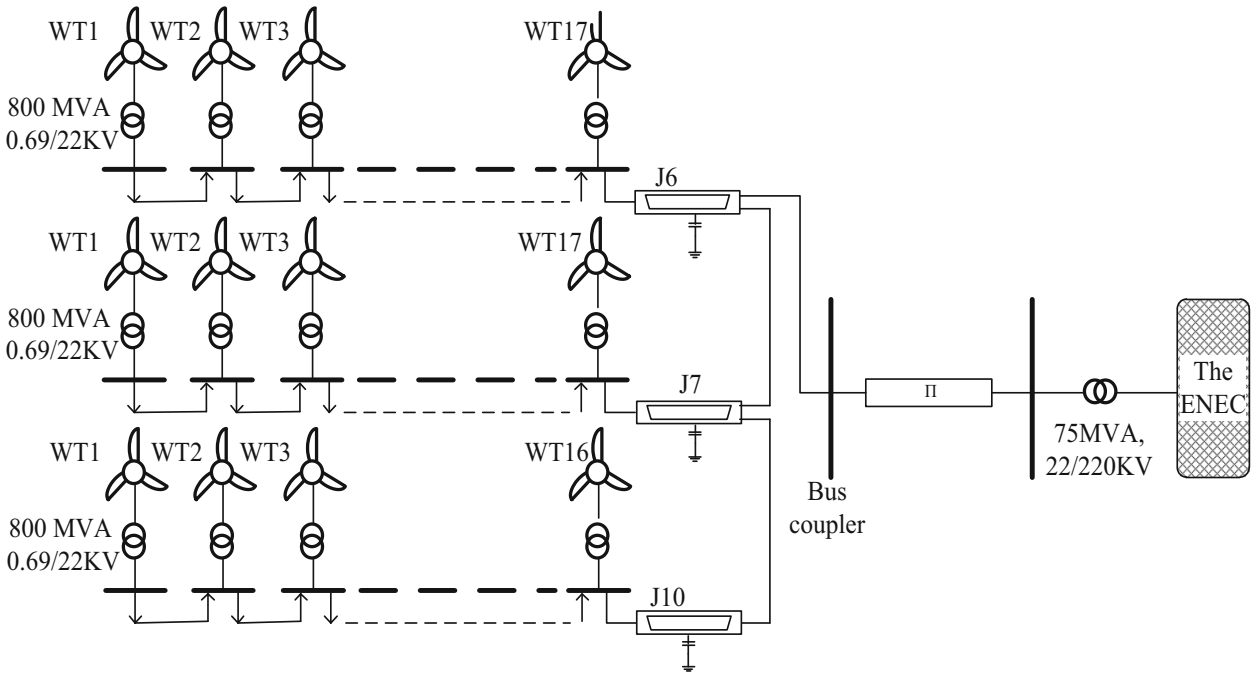

\begin{tabular}{llllll}
\hline Power & \multicolumn{2}{c}{ Rotor } & \multicolumn{3}{l}{ Generator } \\
\hline Rated power & $600.0 \mathrm{~kW}$ & Diameter & $43.0 \mathrm{~m}$ & Type & $\begin{array}{c}\text { Asynchronous } \\
\text { (SCIG) }\end{array}$ \\
Cut-in wind speed & $2.5 \mathrm{~m} / \mathrm{s}$ & Swept area & $1452.0 \mathrm{~m}^{2}$ & Speed, max & $1513.0 \mathrm{rpm}$ \\
Rated wind speed & $15.0 \mathrm{~m} / \mathrm{s}$ & Number of blades & 3 & Voltage & $690.0 \mathrm{~V}$ \\
& & Rotor speed, max & $26.9 \mathrm{rpm}$ & Grid frequency & $50.0 / 60.0 \mathrm{~Hz}$ \\
& Tip speed & $61 \mathrm{~m} / \mathrm{s}$ & & \\
& Hub height & $40.0 ; 50.0 \mathrm{~m}$ & & \\
& & Maximum blade & $1.65 \mathrm{~m}$ & & \\
& width & & & \\
& &
\end{tabular}

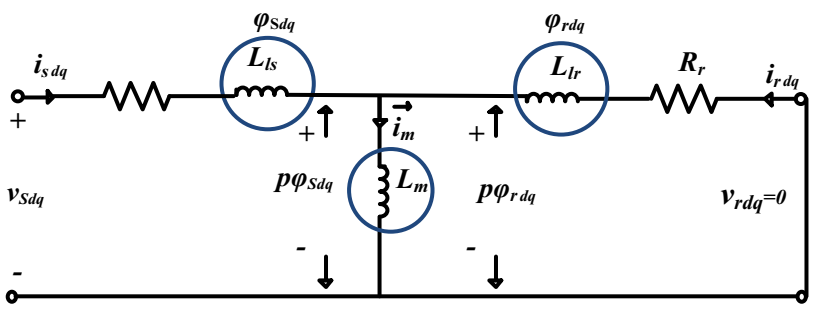

Fig. 3 The SCIG equivalent circuit

The main feature of Zafarana Wind Park is its construction of several wind farms. This feature facilitates studying the performance of each wind farm separately. In this paper, Zafarana Z1 wind farm has been chosen to represent the studied case. The encouraging reasons for choosing Z1can be summarized as follows:

- Zafarana Z1 wind farm is the first stage of Zafarana Wind Park which is already connected to ENEN

- Zafarana Z1 wind farm is based on asynchronous generator. This type faces many difficulties to remain connected to the grid during abnormal operation condition of the grid.
Zafarana Z1 wind farm is composed of 50 Nordex$\mathrm{N} 43$ wind turbines. Each wind turbine produces 0.6 MW, $0.690 \mathrm{KV}, 50 \mathrm{~Hz}$ at $13 \mathrm{~m} / \mathrm{s}$ rated wind speed. The separated distance between wind turbines is $60 \mathrm{~m}$, and the separated distance between rows is 800 m. 50 Nordex-N43 wind turbines are connected to three feeders (J6, J7 and J10) through 800 MVA, 0.69/22 KV coupling transformers. J6 and J7 contain 17 wind turbines, while $\mathrm{J} 10$ contains 16 wind turbines. The three feeders are connected to bus coupler to inject the produced power to a $220 \mathrm{KV}$ transmission system through 75 MVA, 22/220 KV transformer [16-19]. Figure 2 shows the single line diagram (SLD) of Z1 wind farm.

\section{Modeling and parameters of Zafarana Z1 wind farm wind turbines}

Zafarana Z1 wind farm composes 50 wind turbines/ NordexN43. The parameters of Nordex-N43 are given in Table 2 [16-19, 32, 33].

The equations which represent the mathematical model of SCIG wind turbines were introduced in many books and 
articles [34-36]. The induction generator's (IG) equivalent circuit is shown in Fig. 3.

This SCIG equivalent circuit can be used to write the direct and quadratic $(\mathrm{d}-\mathrm{q})$ representation of SCIG with respect to the synchronous as follows [34-36]:

$$
\left\{\begin{array}{l}
v_{d s}=\frac{d \varphi_{d s}}{d t}-\omega_{s} \varphi_{q s}+R_{s} i_{d s} \\
v_{q s}=\frac{d \varphi_{q s}}{d t}+\omega_{s} \varphi_{d s}+R_{s} i_{q s} \\
v_{d r}=\frac{d \varphi_{d r}}{d t}-s \omega_{s} \varphi_{q r}+R_{r} i_{d r}=0 \\
v_{q r}=\frac{d \varphi_{q r}}{d t}+s \omega_{s} \varphi_{d r}+R_{r} i_{q r}=0
\end{array}\right.
$$

$$
\left[\begin{array}{c}
\varphi_{d s} \\
\varphi_{q s} \\
\varphi_{d r} \\
\varphi_{q r}
\end{array}\right]
$$$$
=\left[\begin{array}{cccc}
\left(L_{l s}+L_{m}\right) & 0 & & 0 \\
0 & \left(L_{l s}+L_{m}\right) & L_{m} & L_{m} \\
L_{m} & 0 & 0 & 0 \\
0 & L_{m} & \left(L_{l r}+L_{m}\right) & \left(L_{l r}+L_{m}\right)
\end{array}\right]\left[\begin{array}{c}
i_{d s} \\
i_{q s} \\
i_{d r} \\
i_{q r}
\end{array}\right]
$$

with the transmission line and quadratic to the line current. The injected voltage has the ability to achieve two functions: enhancing the power flow by changing the overall impedance of the transmission line and regulating the voltage by controlling the reactive power at the connection point [42]. Figure 4 shows the equivalent circuit and The SLD of SSSC.

From the SLD of SSSC, the SSSC can be connected to any one of the two buses of transmission line. One of the two buses is the sending bus (m), and the other bus is the receiving end bus (n). From the equivalent circuit of SSSC, the current equation can be written as follows [42]:

$$
\left[\begin{array}{c}
I_{m} \\
I_{n}
\end{array}\right]=\left[\begin{array}{ccc}
Y_{L} & -Y_{L} & -Y_{L} \\
-Y_{L} & Y_{L} & Y_{L}
\end{array}\right]\left[\begin{array}{c}
V_{m} \\
V_{n} \\
V_{s s}
\end{array}\right]
$$

where $Y L=1 / Z L$ and represents the admittance of the transmission line. $V m$ and $I m$ the voltage and current of bus $\mathrm{m} . \mathrm{Vn}$ and $I n$ the voltage and current of bus $n$. The active power and reactive power at the receiving end bus $n$ are given by [43]:

$$
P=\frac{V_{m} V_{n}}{X_{L}} \sin \left(\delta_{m}-\delta_{n}\right)
$$

$$
\left[\begin{array}{c}
i_{d s} \\
i_{q s} \\
i_{d r} \\
i_{q r}
\end{array}\right]=\left[\begin{array}{clll}
\frac{\left(L_{l r}+L_{m}\right)}{\left(L_{l s}+L_{m}\right)\left(L_{l r}+L_{m}\right)-L_{m}^{2}} & 0 & \frac{\left(L_{l r}+L_{m}\right)}{\left(L_{l s}+L_{m}\right)\left(L_{l r}+L_{m}\right)-L_{m}^{2}} & 0 \\
0 & \frac{-L_{m}}{\left(L_{l s}+L_{m}\right)\left(L_{l r}+L_{m}\right)-L_{m}^{2}} & \frac{-L_{m}}{\left(L_{l s}+L_{m}\right)\left(L_{l r}+L_{m}\right)-L_{m}^{2}} \\
\frac{-L_{m}}{\left(L_{l s}+L_{m}\right)\left(L_{l r}+L_{m}\right)-L_{m}^{2}} & 0 & \frac{-L_{m}}{\left(L_{l s}+L_{m}\right)\left(L_{l r}+L_{m}\right)-L_{m}^{2}} & 0 \\
0 & \frac{-L_{m}}{\left(L_{l s}+L_{m}\right)\left(L_{l r}+L_{m}\right)-L_{m}^{2}} & \frac{-L_{m}}{\left(L_{l s}+L_{m}\right)\left(L_{l r}+L_{m}\right)-L_{m}^{2}}
\end{array}\right]\left[\begin{array}{c}
\varphi_{d s} \\
\varphi_{q s} \\
\varphi_{d r} \\
\varphi_{q r}
\end{array}\right]
$$

The electrical torque of SCIG and DFIG in terms of $d-q$ components of current and flux of the stator and rotor can be obtained as follows [34, 37-41]:

$$
T_{e}=\left\{\begin{array}{c}
\frac{3 P}{2}\left(i_{q s} \varphi_{d s}-i_{d s} \varphi_{q s}\right) \\
\frac{3 P L_{m}}{2 L_{r}}\left(i_{q s} \varphi_{d r}-i_{d s} \varphi_{q r}\right) \\
\frac{3 P L_{m}}{2}\left(i_{q s} i_{d r}-i_{d s} i_{q r}\right)
\end{array}\right.
$$

Equation (4) shows three expressions for electrical torque. The three expressions can be used depending on the objective or the aim. Because third expression depends on the $d-q$ components of stator and rotor currents, the third expression is effective used in designing the control system of wind turbines.

\section{Static Synchronous Series Compensator (SSSC)}

The Static Synchronous Series Compensator (SSSC) is the most famous member of series FACTS devices family. The function of SSSC is based on injecting a voltage in series
$Q=\frac{V_{m} V_{n}}{X_{L}}\left(1-\cos \left(\delta_{m}-\delta_{n}\right)\right)$

\subsection{SSSC control system}

Figure 5 shows the SLD of SSSC control system. As shown in Fig. 5, the phase angle is generated by the phase-locked loop (PLL). The $\theta$ is used to generate the quadratic component $V q m$ and $V q n$ of $V m$ and $V n$.

The actual quadratic component of voltage of $m$ and $n$ $V q m$ and $V q n$ buses are computed to produce actual quadratic component ( $\left.V q \_m e g\right)$. This actual quadratic component is compared with the quadratic component of the reference voltage $(V q-r e f)$. The result of this comparison is the signal which is injected to the $\mathrm{AC}$ voltage regulator. The AC voltage regulator generates the quadratic component of the SSSC's voltage (Vqsssc). The direct component of the SSSC's voltage (Vdsssc) is generated by comparing the voltage of DC bus with the reference voltage (Vdc-ref) and injecting the output DC voltage regulator. Figure 6 shows the gains of AC and DC voltage regulators (Kpvac and Kivac) and (Kpvdc and Kivdc) of SSSC. 
Fig. 4 Schematic diagram and equivalent circuit of SSSC

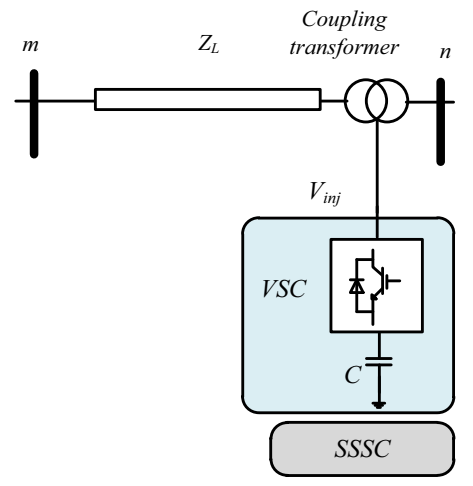

Schematic diagram of SSSC

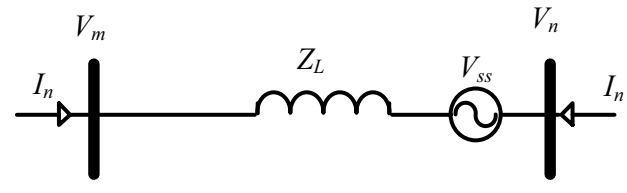

Equivalent circuit of SSSC

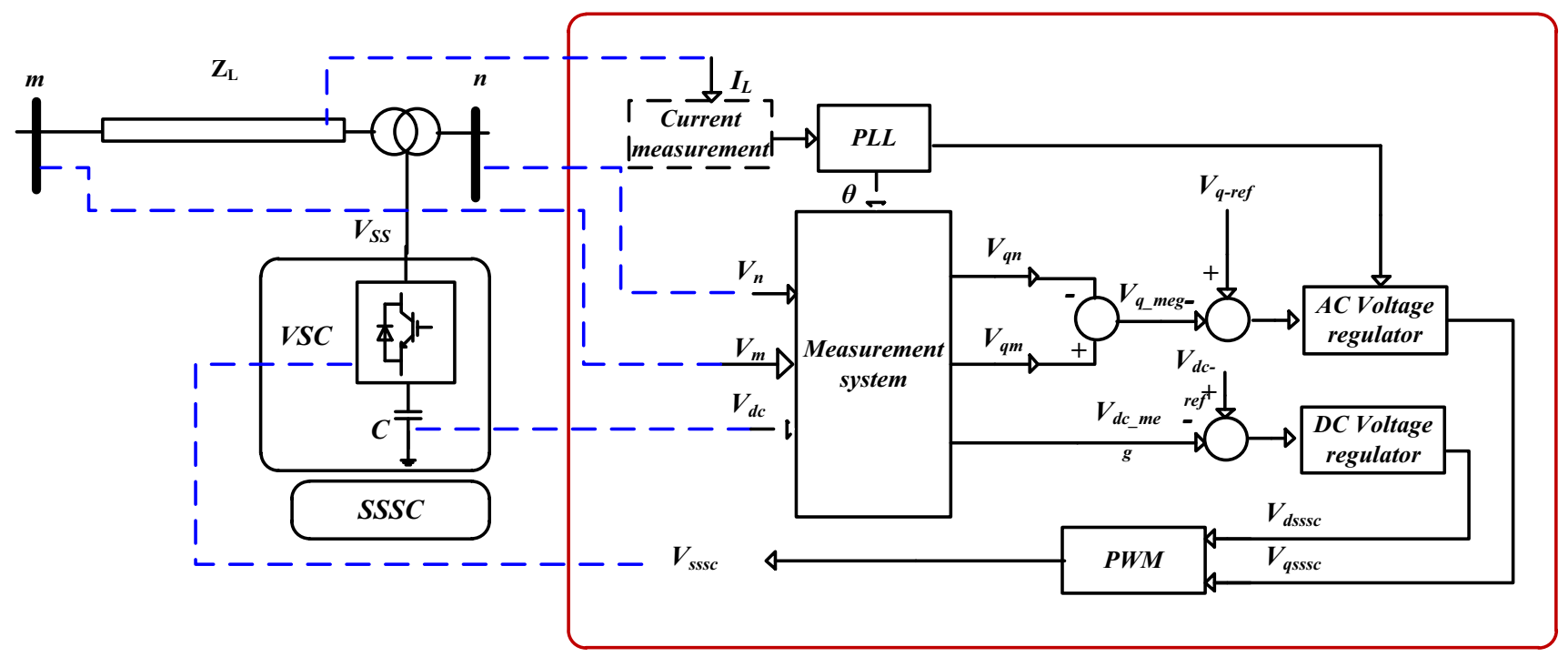

Fig. 5 The SLD of SSSC control system

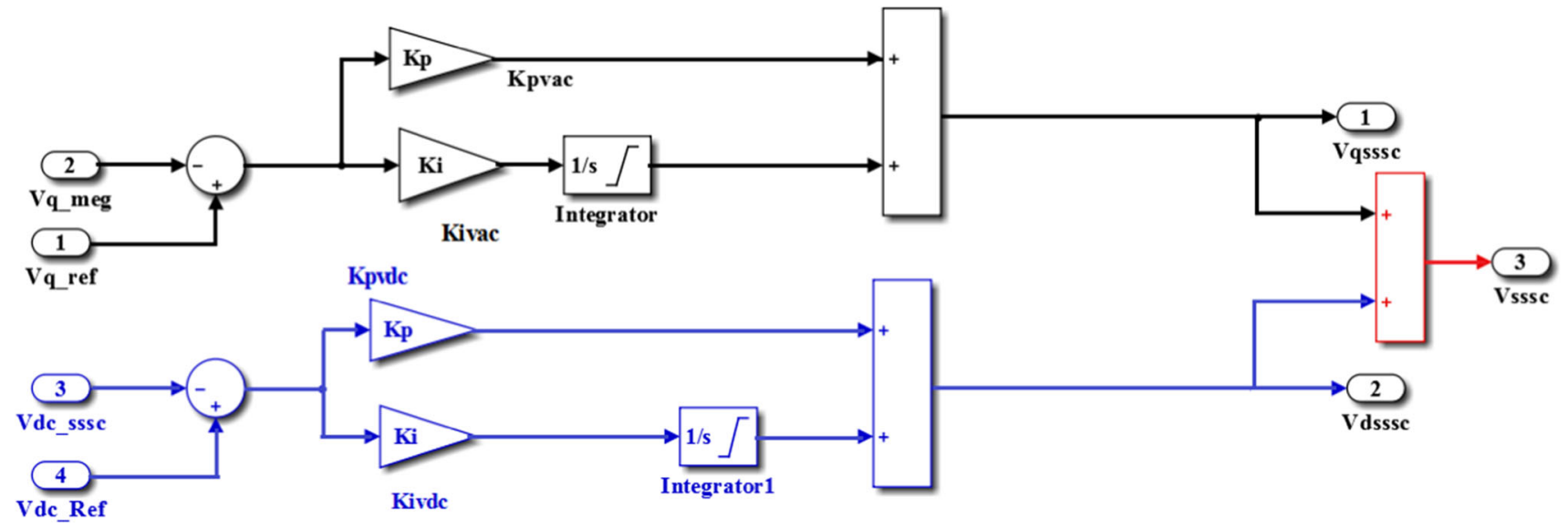

Fig. 6 The gains of AC and DC voltage regulators of SSSC

From Fig. 6 the injected voltage of SSSC $\left(V_{\text {sssc }}\right)$ can be concluded as follows:

$$
\begin{aligned}
V_{d s s s c}= & K_{p v d c}\left(V_{d c \_r e f}-V_{d c s s s c}\right) \\
& +K_{i v d c} \frac{\left(V_{d c \_r e f}-V_{d c s s s c}\right)}{s}
\end{aligned}
$$




$$
\begin{aligned}
& V_{q s s s c}=K_{\text {pvac }}\left(V_{q_{-} r e f}-V_{q \_m e g}\right) \\
& +K_{i v d c} \frac{\left(V_{q_{-} r e f}-V_{q_{-} m e g}\right)}{s} \\
& \begin{aligned}
= & \left(K_{p v d c}\left(V_{d c \_r e f}-V_{d c s s s c}\right)+K_{i v d c} \frac{\left(V_{d c \_r e f}-V_{d c s s s c}\right)}{s}\right) \\
& +j\left(K_{\text {pvac }}\left(V_{q_{-} r e f}-V_{q_{-} m e g}\right)+K_{i v d c} \frac{\left(V_{q_{\_} r e f}-V_{q_{\_} m e g}\right)}{s}\right)
\end{aligned}
\end{aligned}
$$

\section{Lightning attachment procedure optimization algorithm}

LAPO algorithm is one of the recent physical based algorithms. LAPO algorithm mimics the lightning phenomena in nature where a huge amount of electric charges are accumulated inside the cloud which leads to increasing the electrical potential, and then the lightning will strike ground throughout several downward and upward leaders. Lightning attachment is based on four stages which are: (1) Air breakdown (2) Downward movement of Lightning channels (3) Upward leader motion, and (4) Strike point. The steps of the LAPO algorithm can be summarized as follows:

Step 1: Initialization

The initial points of lightning downward leaders (trial spots) are generated randomly as follows:

$X_{i n}^{i}=X_{\min }^{i}+\operatorname{rand} \times\left(X_{\max }^{i}-X_{\min }^{i}\right)$

where $X_{i n}^{i}$ is the trial point. $X_{\min }$ is the minimum limit of $X$, and $X_{\max }$ is its maximum value. rand denotes a random value within $[0,1]$. The fitness functions of the initial points can be found as follows:

$F^{i}=\operatorname{obj}\left(X_{i n}^{i}\right)$

Step 2: The next jumping

All locations of the obtained points are averaged, while their objective functions are given as follows:

$X_{a v r}=\operatorname{mean}\left(X_{i n}\right)$

$F_{a v r}=\operatorname{obj}\left(X_{a v r}\right)$

$X_{a v r}$ is the averaged point. $F_{a v r}$ represents the objective function of the averaged point. The locations of current points are updated based on the average point where to update the point $i$, a random solution $j$ is selected where $i \neq j$. Then the obtained solution is compared with the selected solution as follows:

$$
\begin{aligned}
& X_{\text {new }}^{i}=X^{i}+\operatorname{rand} \times\left(X_{a v r}+X^{j}\right) \quad I F F_{j}<F_{a v r} \\
& X_{n e w}^{i}=X^{i}-\text { rand } \times\left(X_{a v r}+X^{j}\right) \quad I F F_{j}>F_{a v r}
\end{aligned}
$$

\section{Step 3: Section Diminishing}

The updated solution will remain continuous if its value is better than the previous value.

Generated branch will remain continuous if the critical value is less than the electric field of the new test point; otherwise it will fade, and the section diminishing is expressed as follows:

$X_{\text {new }}^{i}=X^{i} \quad I F \quad F_{\text {ts_new }}^{i}<F_{t s}^{i}$

$X^{i}=X_{\text {new }}^{i} \quad$ otherwise

Step 4: Upward Leader Movement

This step defines the movement of upward leader. The updated point based on movement of upward leader is given by

$X_{\text {new }}^{i}=X_{\text {new }}^{i}+$ rand $\times S \times\left(X_{\text {best }}^{i}-X_{\text {worst }}^{i}\right)$

where $X_{\text {best }}^{i}$ represents the best solution, while $X_{w o r s t}^{i}$ represents the worse solutions. $S$ is an exponent operator is given by

$S=1-\left(\frac{t}{t_{\max }}\right) \times \exp \left(-\frac{t}{t_{\max }}\right)$

where $t$ and $t_{\max }$ are the current iteration number and maximum number of iterations.

Step 5: Strike point

When the down leader and the up leader combined together. the lightning is paused at a certain point which known as strike point.

\section{Sine cosine algorithm (SCA)}

SCA is a well algorithm that mimics the sine and cosine functions variation [24]. The movements of populations in the SCA around best solution based on sine and cosine functions are given in (21) as follows:

$X_{i}^{t+1}= \begin{cases}X_{i}^{t}+A_{1} \times \sin \left(C_{2}\right) \times\left|A_{3} X_{\text {best }}^{t}-X_{i}^{t}\right| & A_{4}<0.5 \\ X_{i}^{t}+A_{1} \times \cos \left(C_{2}\right) \times\left|A_{3} X_{\text {best }}^{t}-X_{i}^{t}\right| & A_{4}>0.5\end{cases}$

where $t$ represents the current iteration number. $X_{\text {best }}^{t}$ is the best value among the population. $A_{2}, A_{3}$ and $A_{4}$ are random 

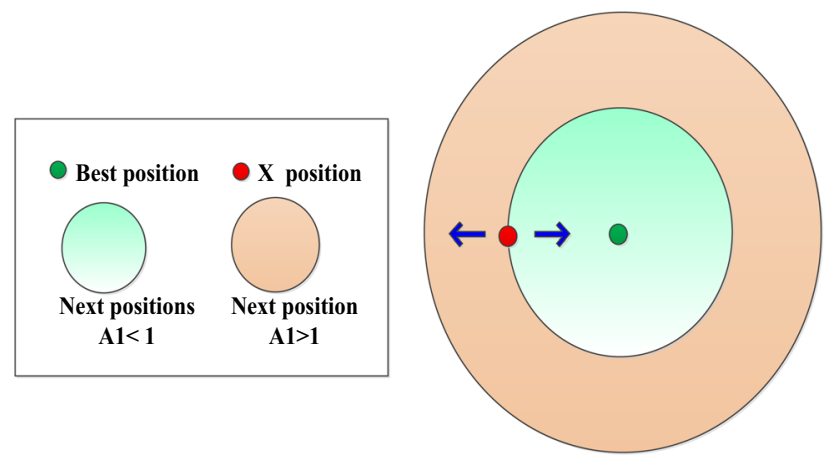

Fig. 7 Trends of the new populations based on $A_{1}$

factors within $[0,1] . A_{1}$ denotes an adaptive value which can be expressed follows:

$A_{1}=k-t \times \frac{K}{t_{\max }}$

where $k$ is a constant value. $t_{\max }$ is the maximum iterations number. It is worth mentioning that $A_{1}$ regulates the trends direction or position of the populations to go outward or inward the best solution as illustrated in Fig. 7.

\section{The methodology of the research}

The main aim of this paper is to enhance the performance of Z1 wind farm as a part of Zafarana wind bark using SSSC. The SSSC is connected in series with transmission line which means that seriousness is great if SSSC is subjected any damage due grid faults. The main challenges are how protect the SSSC from damage and find the value of the control parameters of the SSSC which suit the studied system (Z1 wind farm). The crowbar is used as outer protection for SSSC
Table 3 The protection system of the studied

\begin{tabular}{lll}
\hline Parameters & Value in pu & Delay time in s \\
\hline AC over voltage & 1.10 & 0.1 \\
AC under voltage & 0.75 & 0.1 \\
AC over current & 1.10 & 10 \\
Over speed & 1.05 & 5 \\
Under speed & 1.00 & 5 \\
\hline
\end{tabular}

where SSSC is connected from the side of $\mathrm{Z1}$ wind farm of the bus coupler, while the crowbar is connected from the grid side of the bus coupler as shown in Fig. 8 .

The next table shows the protection system of the studied. The main target of the protection system is to protect the wind farm from over voltage, current and speed and from under voltage, current and speed. The delay time of each type of protection is shown in Table 3 .

In this paper, the value of $\mathrm{AC}$ and $\mathrm{DC}$ voltage regulator of SSSC's control system and the value of crowbar resistance are determined using lightning attachment procedure optimization algorithm (LAPO) and sine cosine algorithm (SCA). LAPO and SCA can call the MATLAB-Simulink model of $\mathrm{Z} 1$ wind farm of Zafarana in every iteration. The optimization of LAPO and SCA is based on three objective functions. The three objective functions are:

1. Minimizing the error signal $(\Delta p)$ which represents the difference between the reference signal of the active power and the accrual active power during fault at the bus coupler.

$$
\Delta p=\left(p_{\text {ref }}-p_{\text {actial }}\right) d t
$$

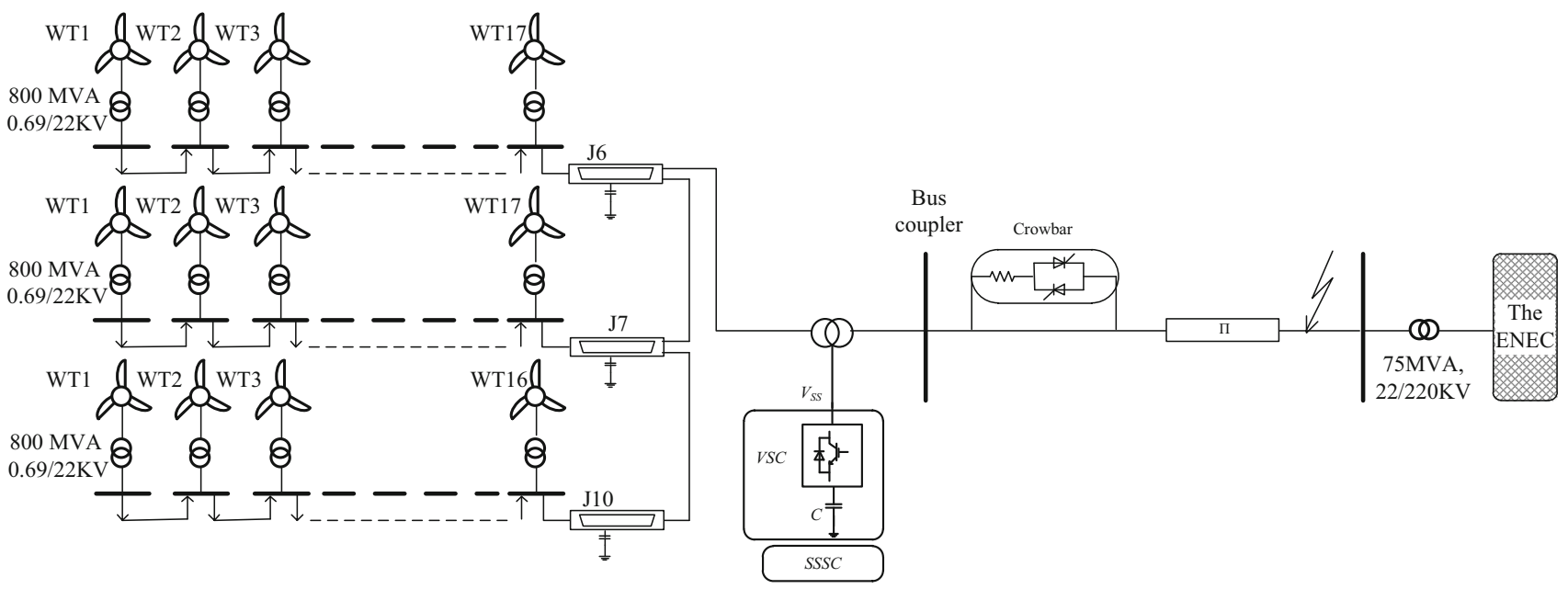

Fig. 8 The SLD of the proposed method and studied system 
2. Minimizing the error signal $(\Delta i)$ which represents the difference between the reference signal of the current and accrual current during fault at the bus coupler.

$$
\Delta i=\left(i_{\text {ref }}-i_{\text {actial }}\right) d t
$$

3. Minimizing the error signal $(\Delta v)$ which represents the difference between the reference signal of the voltage and accrual voltage during fault at the bus coupler.

$$
\Delta v=\left(v_{\text {ref }}-v_{\text {actial }}\right) d t
$$

The next function represents the objective function of LAPO and SCA

$$
F=\left\{\begin{array}{l}
f_{1}=\int_{0}^{t}(\Delta p)^{2} \mathrm{~d} t \\
f_{2}=\int_{0}^{t}(\Delta i)^{2} \mathrm{~d} t \\
f_{3}=\int_{0}^{t}(\Delta v)^{2} \mathrm{~d} t
\end{array}\right.
$$

The values of PI regulators of SSSC $\left(\mathrm{K}_{\mathrm{pvac}}, \mathrm{K}_{\mathrm{ivac}}, \mathrm{K}_{\mathrm{pvdc}}\right.$, $\mathrm{K}_{\mathrm{ivdc}}$ ) are kept in the range $\left[1 \mathrm{e}^{-5}-1000\right]$. The value of crowbar resistance $\left(R_{\text {crow }}\right)$ is kept in the range [0.1-100].

$$
\left\{\begin{array}{l}
K_{\text {pvac }}^{\min } \leq K_{\text {pvac }} \leq K_{\text {pvac }}^{\max } \\
K_{\text {ivac }}^{\min } \leq K_{\text {ivac }} \leq K_{\text {ivac }}^{\max } \\
K_{\text {pvd }}^{\min } \leq K_{\text {pvdc }} \leq K_{\text {pvdc }}^{\max } \\
K_{\text {ivdc }}^{\min } \leq K_{\text {ivdc }} \leq K_{\text {ivdc }}^{\max } \\
R_{\text {crow }}^{\min } \leq R_{\text {crow }} \leq R_{\text {crow }}^{\max }
\end{array}\right.
$$

\subsection{Sliding Mode Control (SMC) applied to SSSC}

$\mathrm{SMC}$ ) is a type of modern nonlinear control. The importance of (SMC) is its ability to ensure that the control system works efficiently without being affected by uncertain factors [44]. In [45], SMC to control the grid and rotor side converters of DFIG based on fuzzy control to tune PI controller. In this paper, SMC is proposed to control the AC and DC voltage regulators of SSSC based on LAPO to tune PI controller. As shown in Fig. 9, the proposed control signals $\left(u_{s m c \_v a c}\right.$ and $u_{s m c_{-} v d c}$ ) are add to $\mathrm{AC}$ voltage and $\mathrm{DC}$ voltage regulators of SSSC, respectively.

To investigate the SMC of AC and DC voltage regulator, the following steps will be followed. The dynamic equation of $V_{\text {qsssc }}$ is defined as follows:

$$
\dot{V}_{q s s s c}=F+V_{q s s s}
$$

where $F$ is the disturbance occurred during operation condition. The error signal is given by

$$
e_{v a c}=V_{q_{-} r e f}-V_{q_{-} m e g}
$$

By adding the additional control signal of SMC ( $u_{\text {smc_vac }}$ ) and substituting Eqs. (29) into (10), Eq. (10) can be written as follows:

$$
V_{q s s s c}=K_{p v a c} e_{v a c}+K_{i v a c} \int e_{v a c} \mathrm{~d} t-F+\dot{V}_{q s s s c}+u_{s m c_{-} v a c}
$$

The switching equation can be defined as follows [45]:

$$
\begin{aligned}
& S=x_{2}+c x_{1} \\
& \left\{\begin{array}{l}
x_{1}=\int e_{v a c} \mathrm{~d} t \\
x_{2}=e_{v a c}
\end{array}\right.
\end{aligned}
$$

The state space of Eq. (31) and derivative of $S$ can be defined as follows:

$$
\begin{aligned}
& \left\{\begin{array}{l}
\dot{x}_{1}=x_{2} \\
\dot{x}_{2}=-K_{i v a c} x_{1}-K_{p v a c} x_{2}-u_{s m c_{-} v a c}-F
\end{array}\right. \\
& \dot{S}=x_{2}\left(c-K_{\text {pvac }}\right)-K_{\text {ivac }} x_{1}-u_{\text {smc_vac }}-F
\end{aligned}
$$

In order to ensure that the system will follow the sliding surface, $u_{\mathrm{smc}}$ has two components $u_{\mathrm{smc} 1}$ and $u_{\mathrm{smc} 2}$; where $u_{\text {smc } \_ \text {vac }}=u_{\text {smc } \_ \text {ac } 1}+u_{\text {smc_ac2 } 2} \cdot u_{\text {smc } \_ \text {ac1 } 1}$ represents the ideal condition of the sliding mode, and $u_{\mathrm{smc} \_ \text {ac } 2}$ is used to reduce the effects of chattering. The ideal condition of the sliding mode will occur when $\mathrm{S}=0 . u_{\text {smc_ac1 }}$ will be equal to the next equation.

$u_{s m c \_a c 1}=x_{2}\left(c-K_{\text {pvac }}\right)-K_{\text {ivac }} x_{1}-F$

In order to reduce the effects of chattering, $u_{\mathrm{smc} 2}$ will be defined as follows [28]:

$u_{s m c \_a c 2}=\eta_{1} \operatorname{sat}(S, \varepsilon)+\eta_{2} S$

$\operatorname{sat}(S, \varepsilon)= \begin{cases}1 & S>\varepsilon \\ \frac{S}{\varepsilon} & \eta_{1} \text { and } \eta_{2}>0 \text { and }\|S\| \leq \varepsilon \\ -1 & S>-\varepsilon\end{cases}$

By substituting Eqs. (35) and (36) into (30), the $V_{\text {qsssc }}$ can be written as follows:

$V_{q s s s c}=\eta_{1} \operatorname{sat}(S, \varepsilon)+\eta_{2} S-F+\dot{V}_{q s s s c}+c * e_{a c}$

By the same way, the SMC of DC voltage regulator can be investigated and Eq. (9) can be written as follows:

$V_{d s s s}=\eta_{3} \operatorname{sat}(S, \varepsilon)+\eta_{4} S-F+\dot{V}_{d s s s c}+c * e_{d c}$ 


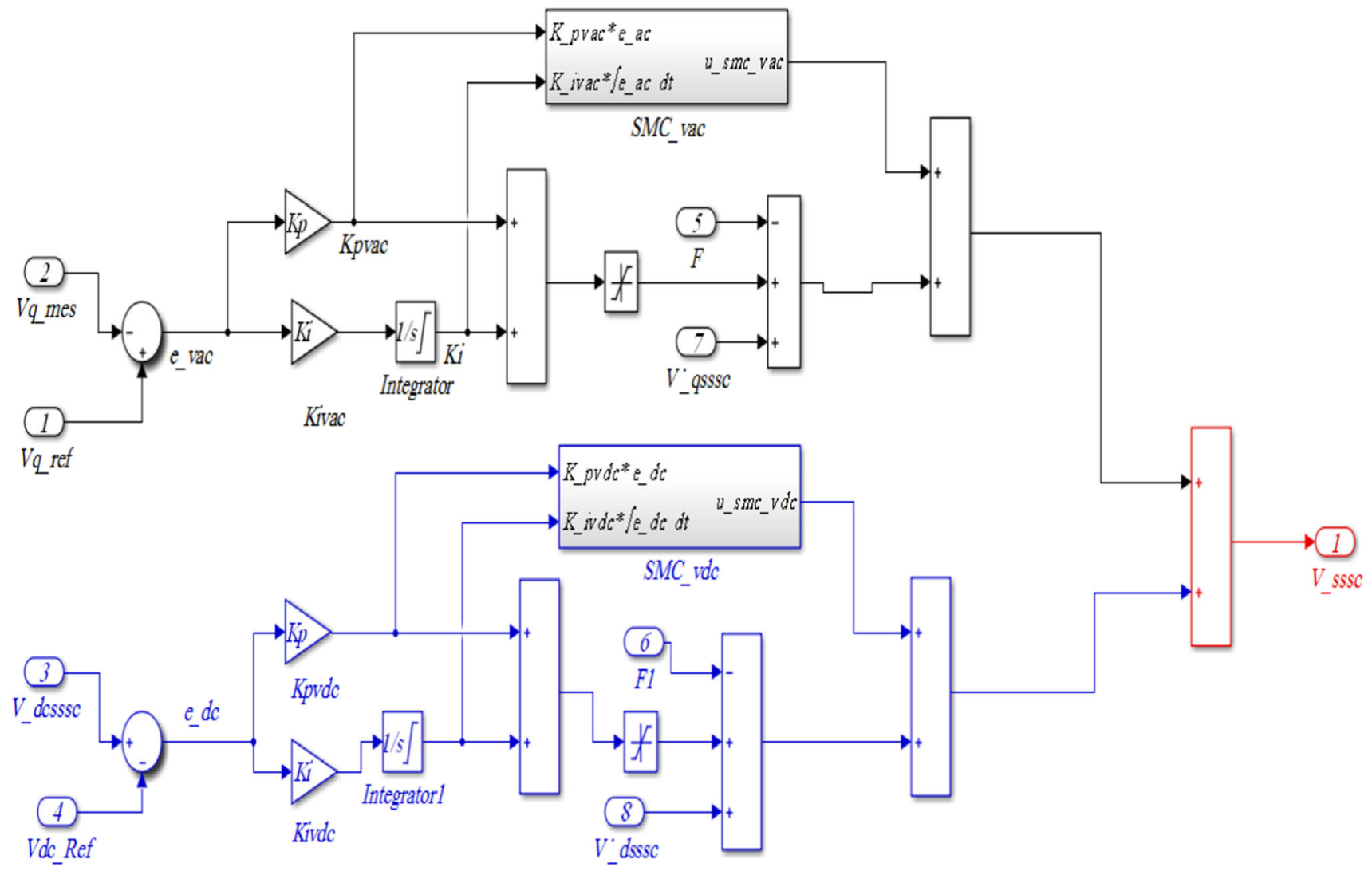

Fig. 9 The AC and DC voltage regulators of SMC-SSSC

Table 4 The optimal values of proposed Cro-SSSC

\begin{tabular}{llccc}
\hline Parameter & Parameter & LAPO & SCA & LAPO-SMC \\
\hline AC voltage regulator of SSSC & $\mathrm{K}_{\mathrm{pvac}}$ & 0.07531 & 0.17651 & 0.08901 \\
& $\mathrm{~K}_{\mathrm{ivac}}$ & 0.04301 & 0.06923 & 0.697 \\
DC voltage regulator of SSSC & $\mathrm{K}_{\mathrm{pvdc}}$ & 0.00092 & 0.00056 & 0.0016 \\
& $\mathrm{~K}_{\mathrm{ivdc}}$ & 0.08453 & 0.044682 & 0.0862 \\
Crowbar resistance & $\mathrm{R}$ & 20.599 & 21.4693 & 15.971 \\
\hline
\end{tabular}

\section{Results and impact of proposed method on Zafarana Z1 wind farm}

This section presents the results of using multi-objective of LAPO and SCA which are to evaluate the optimal values of proposed Cro-SSSC. The optimal values of proposed CroSSSC represent the gains of PI regulators of control system of SSSC and value of crowbar. The case study represents the performance of Zafarana Z1 wind farm during three-phase fault when Cro-SSSC is tuned by LAPO and SCA and without Cro-SSSC.

\subsection{Optimal values of Cro-SSSC obtained by LAPO and SCA}

In order to obtain optimal values of Cro-SSSC using LAPO and SCA, the properties and features of MATLAB program are used to link M-file scripts of LAPO and SCA with proposed MATLAB-Simulink model of Zafarana Z1 wind farm integrated with Cro-SSSC. Table 4 shows the optimal values of proposed Cro-SSSC. Also, the optimal values of proposed Cro-SSSC when SMC is used as an example of nun-liner control method.

\subsection{Obtained results during three-phase fault}

Figure 10 shows the active power of Zafarana Z1 wind farm during three-phase fault when it connected with and without 
Fig. 10 Active power of Zafarana Z1 wind farm (three-phase fault)

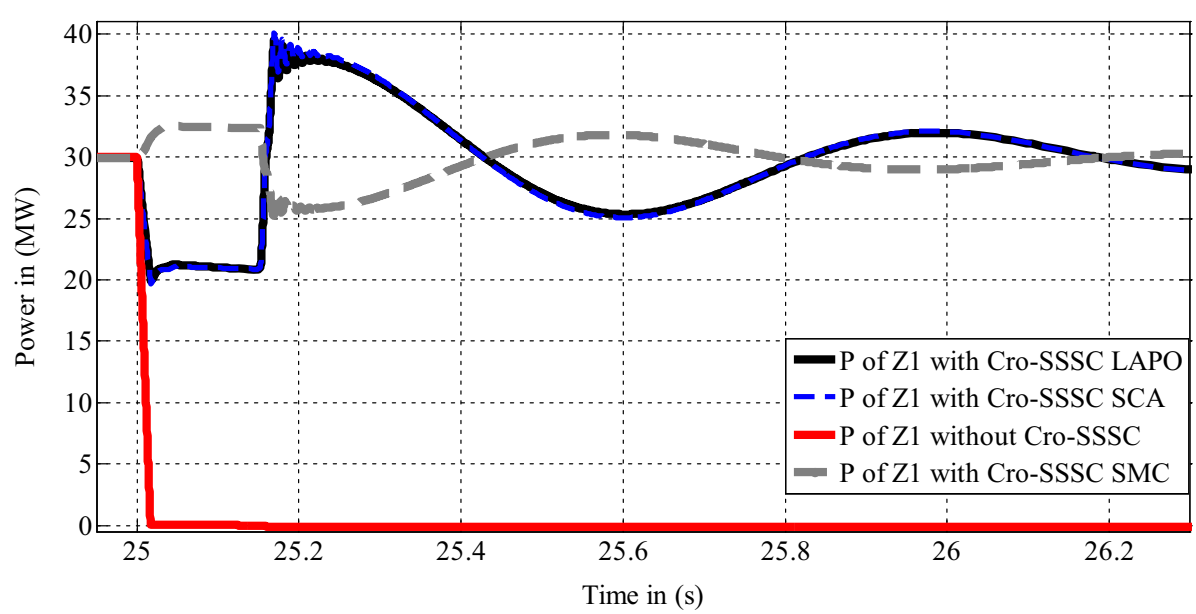

Cro-SSSC. As shown in Fig. 10 when the Zafarana Z1 wind farm is integrated with Cro-SSSC, the active power generated by is $21 \mathrm{MW}$ during the fault period.

This means that it has not separated from the ENEN due to the performance of Cro-SSSC. Unlike the non-use of CroSSSC, the active power of the Zafarana Z1 drops to zero MW. This means, the Zafarana Z1 suffers from complete separation from the ENEN. Also, Fig. 10 shows that the CroSSSC has almost the same performance when it is tuned by LAPO and SCA. Also, Fig. 10 shows when SMC is used as nonlinear control method to control Cro-SSSC has improved the active power produced by Zafarana $\mathrm{Z} 1$ and injects more power to ENEN during the fault. There must be a reason for the dropping in active power of Zafarana Z1 wind farm when there is no connection to Cro-SSSC. To discover this reason, the behaviors of voltage and current have to be observed and studied. Figures 11 and 12 show the voltage and current of Zafarana Z1 wind farm during fault condition.

As shown in Fig. 11, when the Cro-SSSC has not been used, the voltage of Zafarana $\mathrm{Z} 1$ wind farm is dropped to zero. On the other hand, when of Zafarana $\mathrm{Z1}$ wind farm is integrated with the Cro-SSSC, the voltage is only dropped to $0.8 \mathrm{pu}$ and $0.98 \mathrm{pu}$ when SMC is used. Also, the performance of Cro-SSSC when it is tuned by LAPO or SCA is almost the same. As shown in Figs. 10 and 11, both of active power and voltage were dropped to zero from the first moment of fault occurrence. Hence, the time of disconnection of Zafarana $\mathrm{Z} 1$ wind farm from ENEN can be observed. The time of disconnection of Zafarana Z1 wind farm from ENEN can be observed by studying the behavior of current as shown in Fig. 12.

Figure 12 shows that when Zafarana Z1 wind farm is integrated with Cro-SSSC, the lowest value of current is $0.8 \mathrm{pu}$ for both LAPO and SCA. When SMC is used, the lowest value of current is $1.09 \mathrm{pu}$ which sets in the allowable limits of protection system. On other hand, when the Cro-SSSC has not been used the current of Zafarana Z1 wind farm is increased to $2.5 \mathrm{pu}$ at the begging of fault then decreased to $1.5 \mathrm{pu}$. After the occurrence of fault by $0.1 \mathrm{~s}$ (at time equal to $25.105 \mathrm{~s}$ ) the current is dropped to zero. This means that the protection system has disconnected the Zafarana Z1 wind farm from after the delay time of the fastest protection. According to Table 3 the fast protection is the under voltage protection which will disconnect the Zafarana $\mathrm{Z} 1$ wind after $0.1 \mathrm{~s}$, this means that the disconnection is due to the under voltage. The behavior of current at the connection bus will affect the reactive power absorbed by the Zafarana $\mathrm{Z} 1$ wind farm ENEN. This is shown in Fig. 13 which shows the reactive power of the Zafarana $\mathrm{Z} 1$ wind farm at the connection bus.

When the Zafarana Z1 wind farm is integrated with the Cro-SSSC which is tuned by LAPO, SCA and SMC, the absorbed reactive power of the Zafarana $\mathrm{Z} 1$ wind farm is decreased during fault. The reactive power of the Zafarana $\mathrm{Z} 1$ has returned to steady state value much faster when CroSSSC is controlled by SMC. This decreasing in the absorbed reactive power is consistent with the decreasing in current in case of Zafarana Z1 wind farm is integrated with the CroSSSC. Consequently, the increase in current of Zafarana Z1 wind farm without suing Cro-SSSC will cause increase in the absorbed reactive power by Zafarana Z1 wind farm during fault. This is cleared in Figs. 12 and 13. The performance of current and reactive power of Zafarana Z1 wind farm during fault will reflect on the rotor speed of SCIG wind turbines which are used in Zafarana Z1 wind farm. Figure 14 shows the rotor speed of SCIG wind turbines. As it is cleared from Fig. 14 when the Cor-SSSC has not been used, the rotor speed is increased as the absorbed reactive power by Zafarana $\mathrm{Z} 1$ wind farm increases. In an inverse way, when the Cro-SSSC is used, it can be said that the change in rotor speed is not noticeable, especially when Cro-SSSC is controlled by SMC.

The impact of Cro-SSSC on parameters of Zafarana Z1 wind farm is almost the same in both case of tuning (LAPO and SCA). One the other hand, when Cro-SSSC is controlled 
Fig. 11 Voltage of Zafarana Z1 wind farm

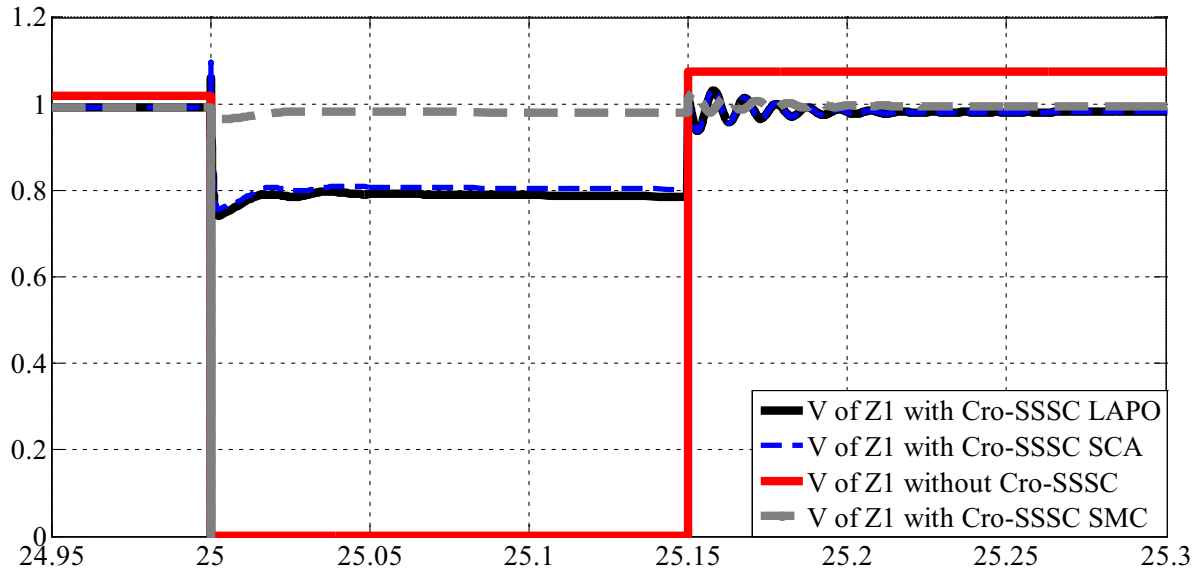

Fig. 12 Current of Zafarana Z1 wind farm (three-phase fault)

Fig. 13 The reactive power of Zafarana Z1 wind farm at the connection bus (three-phase fault)
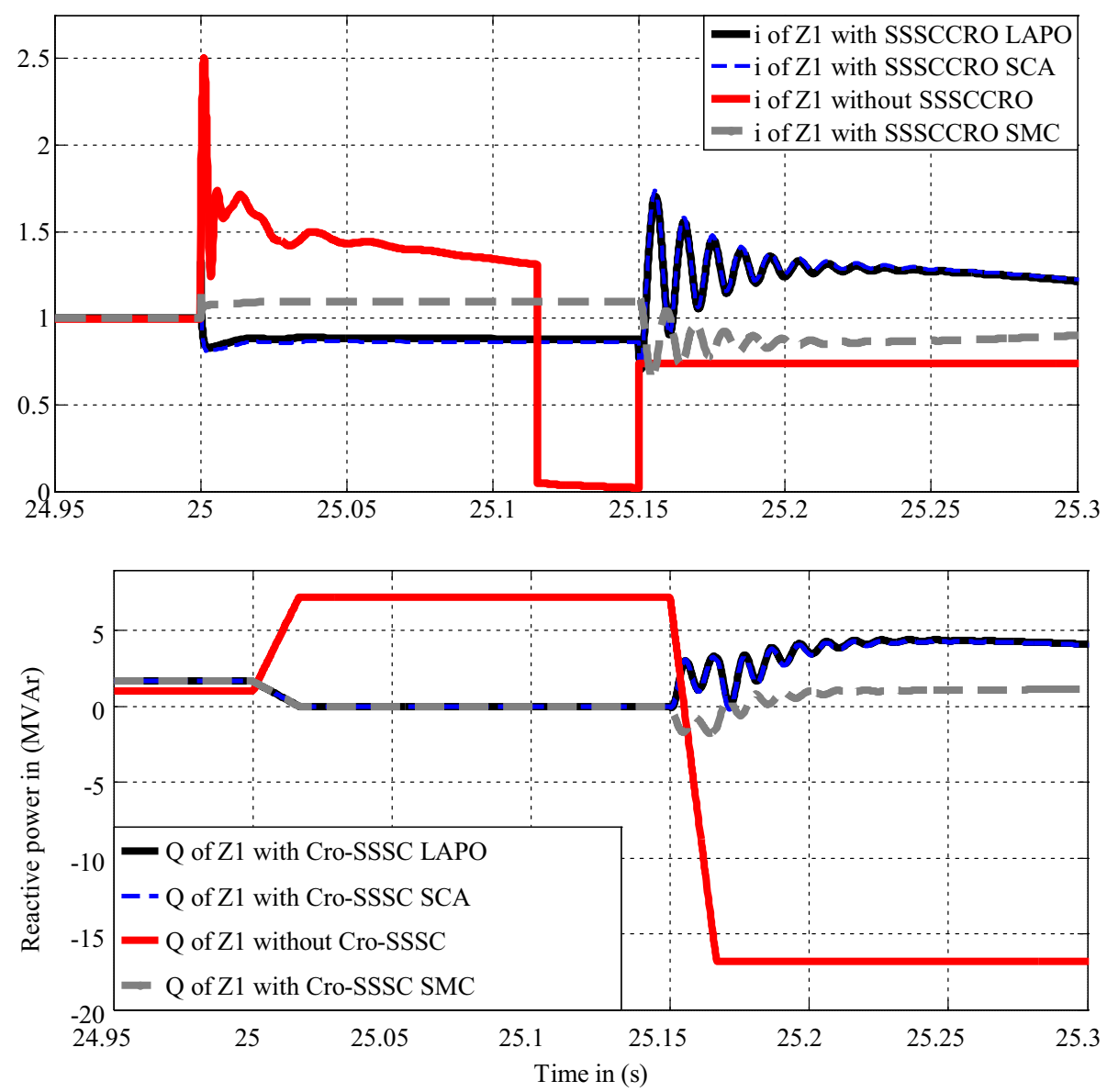

using SMC based on optimization LAPO, this impact is almost non-existent. This means the change in the voltage of DC bus of SSSC will be almost the same in both case of tuning (LAPO and SCA). Figure 15 shows the voltage of DC bus of Cro-SSSC will be almost the same in both case of tuning (LAPO and SCA). As shown in Fig. 15, the impact of using LAPO to tune Cro-SSSC on voltage of DC bus of Cro-SSSC is very close to the impact of using SCA to tune Cro-SSSC.
Also, Fig. 15 shows the ability of the SMC to make the Cro-SSSC follows the path of the sliding surface.

\subsection{Obtained results during three-phase fault}

Figures 16 and 17 show the active power and current of Zafarana Z1 wind farm at the connection bus. As it can be observed, in all cases the Zafarana Z1 wind farm is still connected to the grid. The worst case happened in the absence 
Fig. 14 The rotor speed of SCIG wind turbines (three-phase fault)

Fig. 15 Voltage of DC bus of SSSC in both case of tuning (LAPO and SCA) (three-phase fault)

Fig. 16 Active power of Zafarana Z1 wind farm (single line to ground fault)
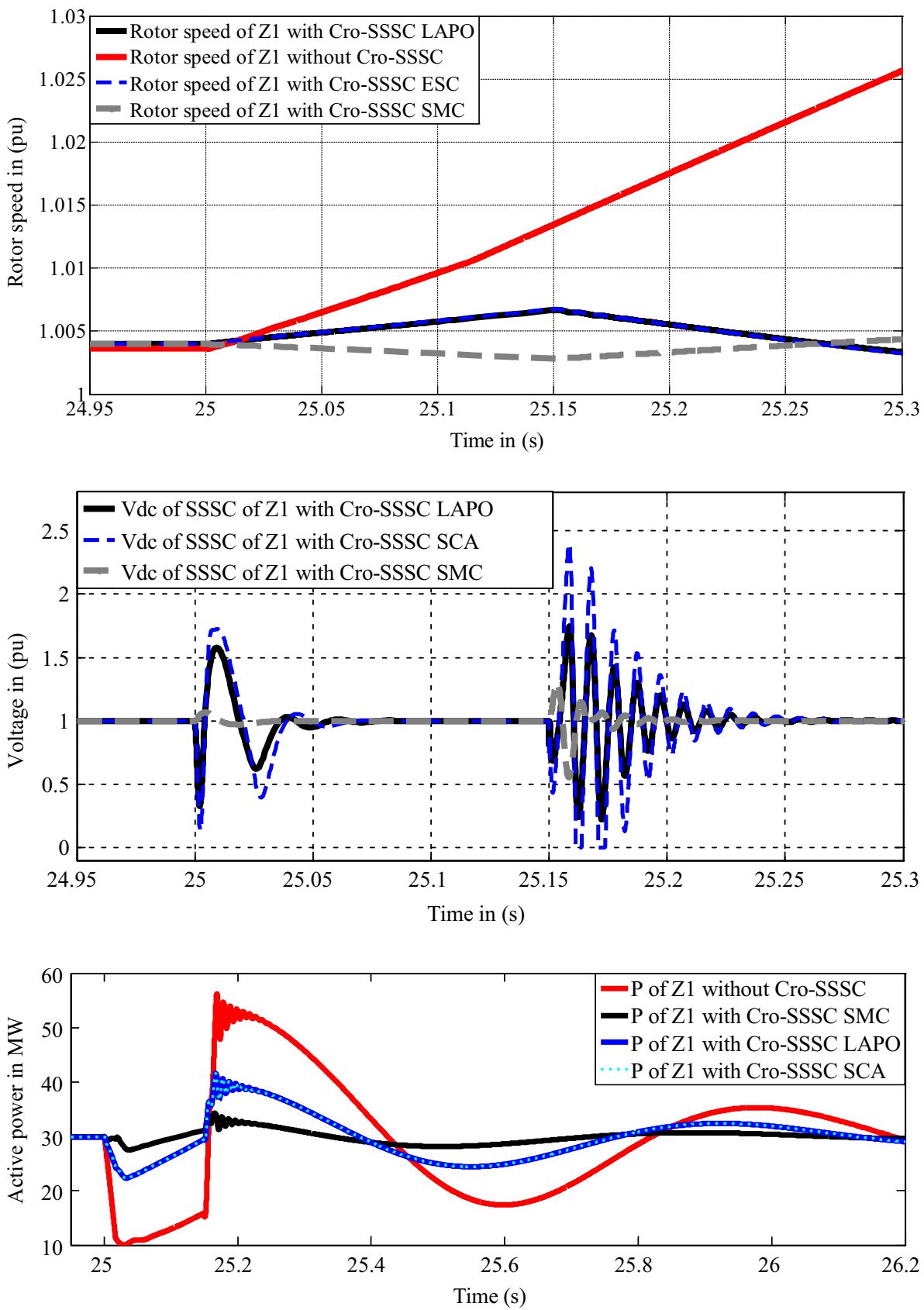

of Cro-SSSC, while the best performance is for Cro-SSSC controlled by SMC based on LAPO.

When LAPO and SCA are used to tune Cro-SSSC, the performance of Zafarana $\mathrm{Z1}$ is almost identical and better than the case of absence of Cro-SSSC. Also, Figs. 16 and 17 show that in the case of Cro-SSSC controlled by SMC based on LAPO, the change in active power and current due to single line fault is very small. According to [46], the absence of one phase will increase the voltage in the other two phase, and hence, the root mean square (rms) value of voltage will be higher than the nominal value; this will happen if the reactive power is increased. This is shown in Fig. 18 which shows voltage of Zafarana Z1 wind farm and Fig. 19 which shows the reactive power of Zafarana Z1 wind farm (single line to ground fault). In the absence of single phase and increasing in absorbed reactive power the rms of voltage will increase in the case of LAPO, SCA and SMC due to the presence of Cro-SSSC. On other hand, when Cro-SSSC is not used, the voltage is decreased and the reactive power is injected from the capacitor bank connected to SCIG wind turbines of Zafarana Z1 wind farm. From Fig. 20, it can be observed that change in DC voltage of Cro-SSSC is from 0.995 to 0.005 pu. Also, the change in case of SMC is lower the LAPO and SCA. This is due to the impact of SMC which drives the 
Fig. 17 Current of Zafarana Z1 wind farm (single line to ground fault)

Fig. 18 Voltage of Zafarana Z1 wind farm (single line to ground fault)

Fig. 19 Reactive power Zafarana Z1 wind farm (single line to ground fault)
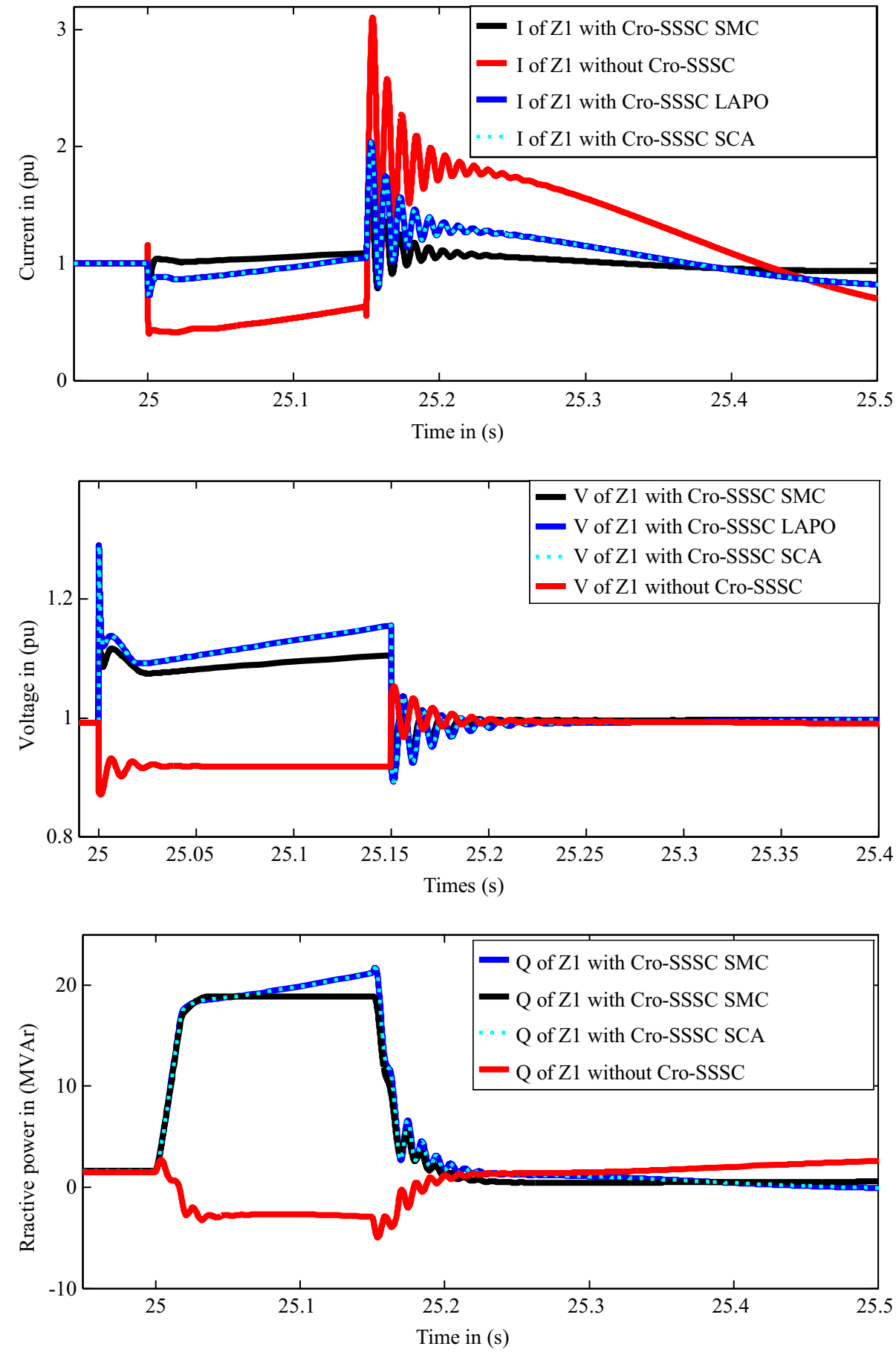

system to around sliding surface. Hence, the change in rotor speed of SCIG wind turbines of Zafarana Z1 wind farm is very small as shown in Fig. 21.

\section{Conclusion}

This research addresses the problem of disconnection of Zafarana wind farm from Egypt national electric network
(ENEN). To solve this problem, a combination of SSSC and crowbar (Cro-SSSC) was used in this paper. Due to the fact that the SSSC is connected in series, the crowbar was used as a safeguard for SSSC from the high current during grid fault. LAPO and SCA were used to evaluate the appropriate values of crowbar's resistance and control gains of SSSC, which is suit the Zafarana wind farm associated with Cro-SSSC. Also, SMC based on LAPO was used as nonlinear control. The performance of Zafarana 
Fig. 20 DC voltage of Cro-SSSC (single line to ground fault)

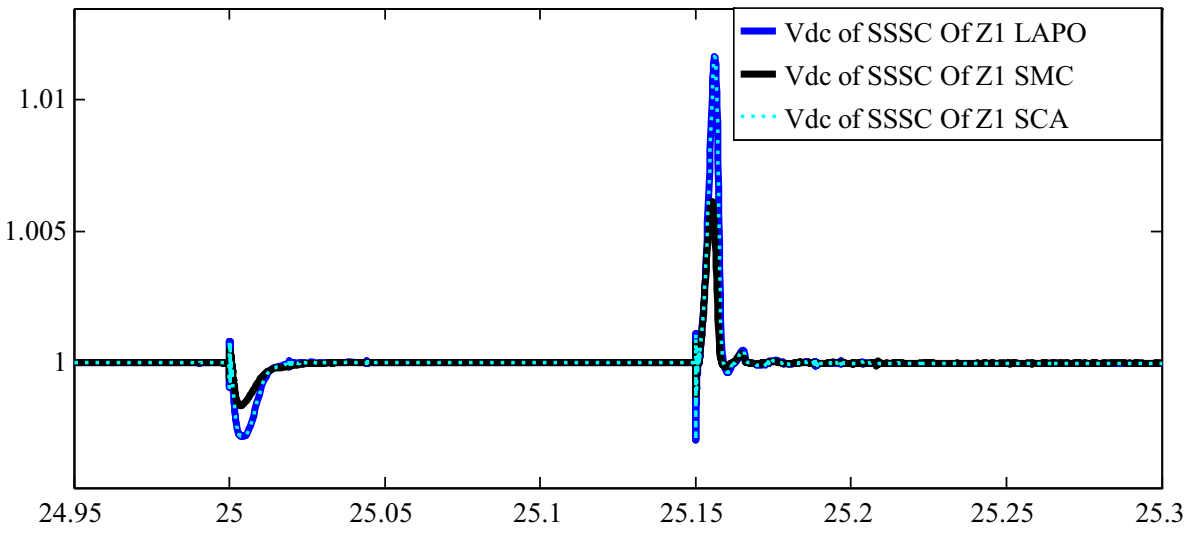

Fig. 21 Rotor speed of Zafarana $\mathrm{Z1}$ wind farm (single line to ground fault)

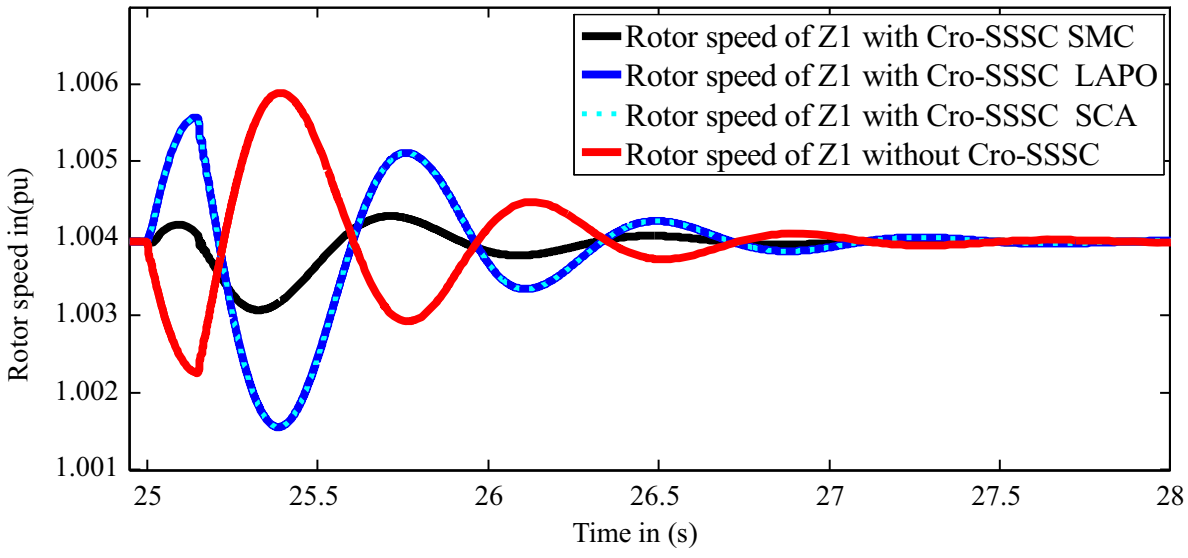

wind farm associated with Cro-SSSC during three-phase fault and single line to ground fault were examined when Cro-SSSC was tuned by LAPO, SCA and when it controlled by SMC. Also, this performance is compared with Zafarana wind farm without Cro-SSSC. The results show that the using Cro-SSSC is not only capable of keeping the continuous connection of Zafarana wind farm but also can keep its current, active power and rotor speed at acceptable limits especially when it is controlled by SMC based on LAPO.

\section{Recommendations}

In this paper, the MALAB Simulink model was built based on the actual data of Zafarana Z1 wind farm. The parameters of Nordex wind turbine -N43 which are used in Zafarana Z1 wind farm are given in Table 2 [16-19, 32, 33]. Hence, it is expected that the results of this research will be very close to the actual application. The authors recommend using Cro-SSSC controlled by SMC base on LAPO in solving the problem of disconnection of Zafarana Z1 wind farm from ENEN.
Funding Open Access funding provided thanks to the CRUE-CSIC agreement with Springer Nature.

Open Access This article is licensed under a Creative Commons Attribution 4.0 International License, which permits use, sharing, adaptation, distribution and reproduction in any medium or format, as long as you give appropriate credit to the original author(s) and the source, provide a link to the Creative Commons licence, and indicate if changes were made. The images or other third party material in this article are included in the article's Creative Commons licence, unless indicated otherwise in a credit line to the material. If material is not included in the article's Creative Commons licence and your intended use is not permitted by statutory regulation or exceeds the permitted use, you will need to obtain permission directly from the copyright holder. To view a copy of this licence, visit http://creativecomm ons.org/licenses/by/4.0/.

\section{References}

1. Omran M (2000) Analysis of solar radiation over Egypt. Theor Appl Climatol 67:225-240

2. Robaa S (2006) A study of solar radiation climate at Cairo urban area, Egypt and its environs. Int J Climatol 26:1913-1928

3. Mortensen NG, Said US, Badger J (2006) Wind atlas for Egypt. In: 3rd Middle East-North Africa renewable energy conference (MENAREC 3) 
4. Elyaalaoui K, Ouassaid M, Cherkaoui M (2018) Primary frequency control using hierarchal fuzzy logic for a wind farm based on SCIG connected to electrical network. Sustain Energy Grids Netw 16:188-195

5. Ahsan S, Siddiqui A (2016) Dynamic compensation of real and reactive power in wind farms using STATCOM. Perspect Sci 8:519-521

6. Heydari-Doostabad H, Khalghani MR, Khooban MH (2016) A novel control system design to improve LVRT capability of fixed speed wind turbines using STATCOM in presence of voltage fault. Int J Electr Power Energy Syst 77:280-286

7. Ibrahim Y, Kamel S, Rashad A, Nasrat L, Jurado F (2019) Performance enhancement of wind farms using tuned SSSC based on artificial neural network. IJIMAI 5:118-124

8. Reddy KR, Ravi K, Shilaja C (2019) Squirrel cage induction generator to 140 bus weak distribution power grid connection using i-UPQC for voltage fluctuations. Microelectron J 92:104607

9. Ibrahim Y, Kamel S, Rashad A, Nasrat L, Jurado F (2019) Performance enhancement of wind farms using tuned SSSC based on artificial neural network. Int J Interact Multimedia Artif Intell 1:1-7

10. Firouzi M, Gharehpetian GB, Mozafari SB (2017) Application of UIPC to improve power system stability and LVRT capability of SCIG-based wind farms. IET Gener Transm Distrib 11:2314-2322

11. Rashad A, Kamel S, Jurado F, Mahmoud K (2018) Performance improvement of various types of induction-based wind farms using center-node unified power flow controller. Int J Control Autom Syst $16: 2644-2655$

12. Jiang H, Zhang C, Zhou T, Zhang Y, Zhang F (2019) An adaptive control strategy of crowbar for the low voltage ride-through capability enhancement of DFIG. Energy Procedia 158:601-606

13. Jiang H, Zhou Z, Jia Y, Zhang Y, Zhang F (2019) Coordinated optimization of DFIG rotor crowbar and DC-chopper resistances based on NSGA-II. Energy Procedia 158:589-594

14. Justo J, Bansal R (2018) Parallel RL configuration crowbar with series RL circuit protection for LVRT strategy of DFIG under transient-state. Electric Power Syst Res 154:299-310

15. Rshad AM, Kamel S, Elkasem AH (2018) Enhancement of combined wind farm performance using crowbar. In: 2018 international conference on innovative trends in computer engineering (ITCE), pp 283-288.

16. Aziz AFA (2011) Studying of Wind farm performance at Zafarana Egypt. Int J Electr Comput Sci IJECS 11:42-51

17. Ahmed MA, Kang YC, Kim Y-C (2015) Modeling and simulation of ICT network architecture for cyber-physical wind energy system. In: 2015 IEEE international conference on smart energy grid engineering (SEGE), pp 1-6

18. Amin AM, Mahfouz MMA, Youssef EB (2011) Improvement integration of Zafarana Egypt wind farm connected to the unified power grid. Int Electr Eng J (IEEJ) 1:514-522

19. Fouad A, Elshahed M, Sayed M, Gilany M (2019) Harmonic resonance overvoltage due to main transformer energization in large wind farms, Zafarana, Egypt. Ain Shams Eng J 10:731-743

20. Nematollahi AF, Rahiminejad A, Vahidi B (2017) A novel physical based meta-heuristic optimization method known as Lightning Attachment Procedure Optimization. Appl Soft Comput 59:596-621

21. Nematollahi AF, Rahiminejad A, Vahidi B (2019) A novel multiobjective optimization algorithm based on Lightning Attachment Procedure Optimization algorithm. Appl Soft Comput 75:404-427
22. Youssef H, Kamel S, Ebeed M (2018) Optimal power flow considering loading margin stability using lightning attachment optimization technique. In: 2018 Twentieth international middle east power systems conference (MEPCON), pp 1053-1058

23. El-sattar SA, Kamel S, Tostado M, Jurado F (2018) Lightning attachment optimization technique for solving optimal power flow problem. In: 2018 Twentieth international middle east power systems conference (MEPCON), pp 930-935

24. Mirjalili S (2016) SCA: a sine cosine algorithm for solving optimization problems. Knowl-Based Syst 96:120-133

25. Mirjalili SM, Mirjalili SZ, Saremi S, Mirjalili S (2020) Sine cosine algorithm: theory, literature review, and application in designing bend photonic crystal waveguides. In: Nature-inspired optimizers. Springer, pp 201-217

26. Attia A-F, El Sehiemy RA, Hasanien HM (2018) Optimal power flow solution in power systems using a novel Sine-Cosine algorithm. Int J Electr Power Energy Syst 99:331-343

27. Ravisekar R, Srinivasan K (2020) Optimal reactive power dispatch with series and shunt facts evices using sine cosine algorithm. Int J Adv Res Eng Technol (IJARET) 11:90-109

28. Suleiman HU, Mu'azu MB, Zarma TA, Salawudeen AT, Thomas S, Galadima AA (2018) Methods of chattering reduction in sliding mode control: a case study of ball and plate system. In: 2018 IEEE 7th international conference on adaptive science \& technology (ICAST), pp 1-8

29. Azizi A, Nourisola H, Shoja-Majidabad S (2019) Fault tolerant control of wind turbines with an adaptive output feedback sliding mode controller. Renewable Energy 135:55-65

30. Hinda A, Khiat M, Boudjema Z (2019) Fuzzy second order sliding mode control of a unified power flow controller. Электротехника и электромеханика

31. Berrada Y, Boumhidi I (2020) New structure of sliding mode control for variable speed wind turbine. IFAC Journal of Systems and Control 14:100113

32. E. New and R. E. Association (2018) NREA Annual Report

33. E. New and R. E. Association (2015) NREA Annual Report

34. Wu B, Lang Y, Zargari N, Kouro S (2011) Power conversion and control of wind energy systems. Wiley, New York

35. Simoes MG, Farret FA (2011) Alternative energy systems: design and analysis with induction generators, vol 13. CRC Press, Cambridge

36. Rashad A, Kamel S, Jurado F, Aleem SHA (2018) Stability of distribution networks with wind turbines. In: Electric distribution network management and control. Springer, pp 281-308

37. Muyeen S (2012) Wind energy conversion systems. Springer, Berlin

38. Ackermann T (2005) Wind power in power systems. Wiley, New York

39. Burton T, Jenkins N, Sharpe D, Bossanyi E (2011) Wind energy handbook. Wiley, New York

40. Heier S (2014) Grid integration of wind energy: onshore and offshore conversion systems. Wiley, New York

41. Gharehpetian GB, Agah SMM (2017) Distributed generation systems: design, operation and grid integration. Elsevier Science, New York

42. Acha E, Fuerte-Esquivel CR, Ambriz-Perez H, Angeles-Camacho C (2004) FACTS: modelling and simulation in power networks. Wiley, New York

43. Chauhan S, Bhullar S (2013) Power flow improvement in transmission network using SSSC. Int J Eng Res Technol (IJERT) 2

44. Morshed MJ, Fekih A (2017) A new fault ride-through control for DFIG-based wind energy systems. Electric Power Syst Res 146:258-269 
45. Li S, Wang H, Tian Y, Aitouch A, Klein J (2016) Direct power control of DFIG wind turbine systems based on an intelligent proportional-integral sliding mode control. ISA Trans 64:431-439
46. Bikić KC, Gazdović M, Kelemen F, Lojpur A (2017) Transferred voltages due to single phase earth fault on power transformers. Procedia Eng 202:305-311

Publisher's Note Springer Nature remains neutral with regard to jurisdictional claims in published maps and institutional affiliations. 